\title{
Research on the Development of Campus Football Culture Based on the Background of Undertake Concept_— Taking Jiangxi Independent Colleges as an Example
}

\author{
Chen Huan, Zhou Rui, Guo Yifeng \\ Nanchang University College of Science and Technology, Jiangxi, 330029, China
}

Keywords: Undertake concept, Campus football culture, Development path

\begin{abstract}
Using expert consultation method, questionnaire survey method and the mathematical statistics method, and based on the background of the idea of the campus football culture connotation, Jiangxi Province, the status of campus football culture and campus football construction path is studied. The results show that the campus football culture has rich connotation, its hierarchical structure includes material culture system, system culture system and spiritual culture system; Jiangxi campus football league is very heavy football culture construction, and school level is to be strengthened, especially school football ecology Environment and the construction of football culture; campus football culture should be clear to the student-oriented value orientation, pay attention to dig a good campus football spirit, the establishment of a good campus football culture order, to create a special campus football culture activities to strengthen the campus football material culture.
\end{abstract}

\section{Introduction}

The development of campus football culture and the construction of campus football culture can enable more students to understand and feel the fun of football, to cultivate students' soccer interest and sports spirit, to promote the sustainable development of football, for this has a positive impact to the progress of football in China[1].

During the period of Brazil World Cup in 2014, many people stayed up all night, only to see the world's top team style. But in watching this session of the World Cup will inevitably have some regret, that is, there is no Chinese players figure. China's soccer team is difficult to break out of Asia, the Chinese women's football has gradually faded out of the football case, this is not optimistic about the status[2], so that we have to look at the development of Chinese football in some of the problems.

At present, with the "sun sports" to carry out, many colleges and universities have also increased the importance of extracurricular sports activities. Football project has always been one of the college students favorite sports, to carry out some football league, promote the development of campus football, also to strengthen the construction of campus football culture[3], which has also played a great role in promoting the construction of campus culture.

Campus football culture is composed of material culture, spiritual culture, behavioral culture and institutional culture constitute. Among them, the material culture as the basic prerequisite for carrying out football activities, belongs to the basic category; spiritual culture is more inclined to ideology, belong to the target (direction) category; institutional culture is to regulate the campus football activities to develop , Which belongs to the basic guarantee conditions[4] the behavioral culture is related to the behavior of regulating and restricting the students' soccer activities, belongs to the basic norm.So, the basic relationship between these cultures is shown in Figure 1[5]. 


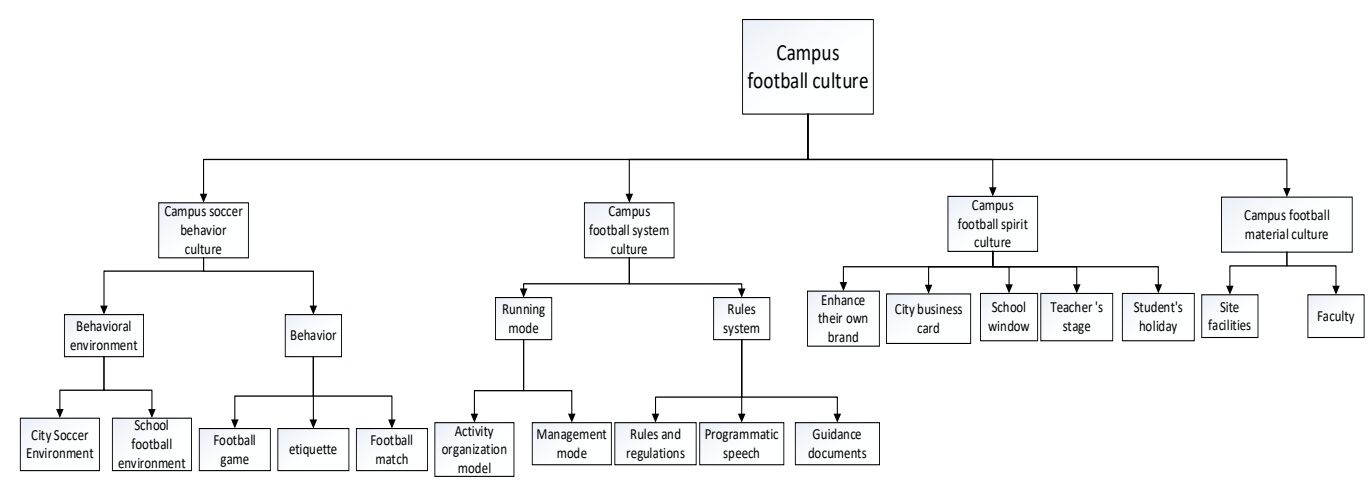

Fig.1 The basic embodiment of campus football culture

Since the 18th Party Congress, General Secretary Xi Jinping repeatedly stressed that party members and cadres, especially leading cadres should be dare to play, dare to adhere the principle, and take the lead in demonstration, the above rate[6]. The concept of undertake, also applies to the football culture development of our Jiangxi Province independent university campus. Dare to "big undertake", with distinctive characteristics of the times[7].

This concept is not noly the time of the exam, but also as a sports teacher of our future account of Chinese football account[8]. By studying the construction of campus football culture, we expect to train a kind of college students who have the responsibility, have the attitude, and this has a good effect for the future development of society.

Therefore, independent colleges and universities of Jiangxi Province should take the campus football culture as a top priority. Now we must establish a new socialist culture, cultivate a new generation of socialism, and with the most able to reflect the spirit of the times of literature and art and cultural activities to cultivate people's sentiments, enrich people's spiritual life[9].

Therefore, this article relies on the spirit of playing spirit, taking the promotion of soccer activities of independent colleges and universities in Jiangxi Province as the background, focusing on the establishment and development of campus football league in Jiangxi province, focusing on the connotation of campus football culture and its construction path, aiming at enriching and perfecting the theoretical system of campus football[10].Constructing and scientific using campus football culture is to drive the sustainable development of campus football, to drive the development and solid progress of the fundamental case and a variety of complementary measures[11]. In view of the characteristics of school education and teachingmethods, the type of campus football culture and its construction, only with the discipline teaching, school normal physical education and teaching, routine sports activities, and school, inter-school football activities, so that campus football and campus football culture can be the power between each other.

\section{Research objects and methods}

\section{Research objects}

This paper takes the status quo of football culture construction and the construction of campus football in Jiangxi province as the research objects.

\section{Research methods}

\section{Interview method}

During the course of the study, students and teachers in independent colleges and universities in Jiangxi Province were interviewed to discuss the construction of football culture in Jiangxi province by discussing the individual visits of the school leaders and the relevant teachers of the teaching and research group. Opinions and provide original information for the study of the subject.

\section{Questionnaire survey method}

By reviewing the literature and follow the basic requirements of the relevant questionnaire design, combining with the views of mentors and relevant teachers, we determined the content of the study in order to understand the students on the campus football culture needs, the recognition of the construction of campus football culture, listen to students suggestions, to understand the 
school campus football culture construction problems. According to the above related content wedesigned the questionnaires. In order to ensure the scientific nature of the questionnaire, we also had asked relevant experts on the questionnaire made a change, and finally formating a formal questionnaire[12]. The initial preparation of the campus football, including the spirit of culture, material culture, institutional culture and behavioral culture 4 first-class indicators, 8 secondary indicators, 30 three indicators (fig.2).

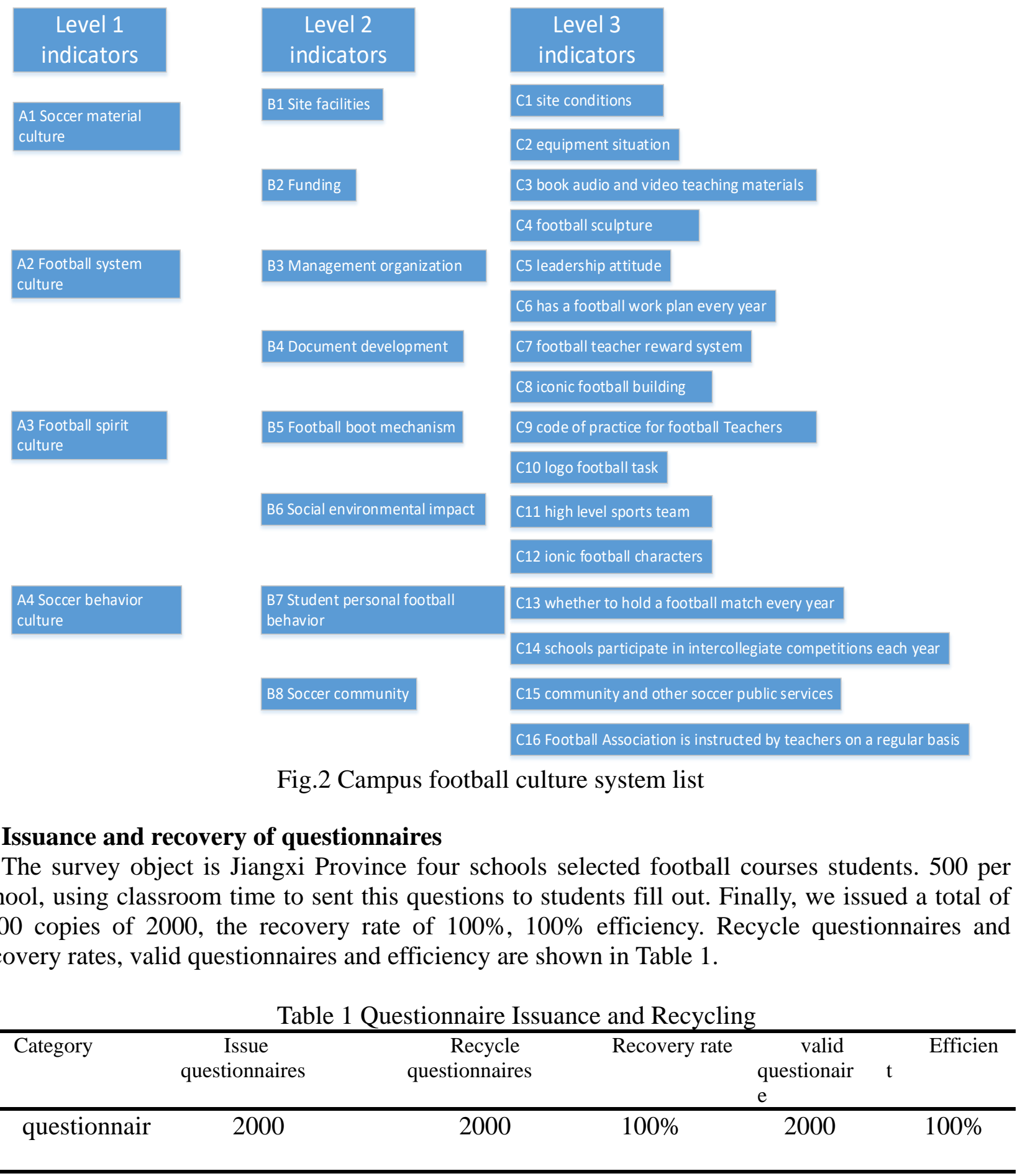

\section{Indicator statistics}

The questionnaire included two parts: scoring and indexing. The indicators in accordance with the "important, more important, general, less important, not important", were given "9,7,5,3,1" score. In statistics, for a group of data average and the trend of the description of the commonly used average of the trend, so with the arithmetic mean of the indicators to express the concentration of experts on the trend, the arithmetic average, indicating high concentration of opinion . When the degree of dispersion is used to describe the degree of dispersion, it has the advantage of not 
counting the unit of measurement and the average level of the data[13]. Therefore, the coefficient of variation is used to denote the degree of discretization and the coefficient of variation of the expert.

Here we assume that: $\mathrm{Xij}$ for the $\mathrm{i}$-th expert on the $\mathrm{j}$-index scoring, a total of $\mathrm{n}$ students, $\mathrm{m}$ indicators.

The concentration of opinion of an indicator

$$
M_{i} / M_{j}=\frac{1}{n} \sum_{i=1}^{n} X_{i j}
$$

The concentration of indicator of the coordination of indicators

$V_{i} / V_{j}=S_{J} / M_{j}$

Among them

$$
S_{j}=\sqrt{\frac{1}{n-1} \sum_{i=1}^{n}\left(X_{i j}-M_{j}\right)}
$$

Mj denotes the arithmetic mean of the index;

$\mathrm{Vj}$ denotes the coefficient of variation of the index;

Sj represents the standard deviation of the indicator.

\section{Analysis of Questionnaire Results}

In the first round of student questionnaire analysis, due to the students on the primary and secondary indicators of higher concentration of views, and the coefficient of variation is small, indicating that students for a level, Secondary indicators hold considerable recognition, do not make more details here, focusing on the three indicators for analysis.

Table 2 The first round of survey part of the three indicators of concentration and coefficient of variation of the list

\begin{tabular}{ccc}
\hline Level 3 indicators & $\begin{array}{c}\text { Opinion concentration } \\
\mathrm{Mj}\end{array}$ & $\begin{array}{c}\text { Coefficient of } \\
\text { variation } \mathrm{Vj}\end{array}$ \\
\hline C3 book audio and video & 5.7 & 0.2310 \\
teaching materials & & \\
C4 football sculpture & 5.8 & 0.1989 \\
C8 iconic football building & 5.5 & 0.2239 \\
C9 code of practice for & 5.9 & 0.2748 \\
football Teachers & & \\
C11 high level sports team & 6.2 & 0.1768 \\
C12 ionic football characters & 6.3 & 0.2871 \\
C15 community and other & 6.9 & 0.1754 \\
soccer public services & & \\
\hline
\end{tabular}

The indicators of the concentration in the three indicators as shown in Table 2, from this table we can be seen, "iconic football construction", "iconic football characters", "community or other football public service", "carry out" sports activities "situation" of these four indicators of variation coefficient is small, indicating that the students have a good degree of coordination of the indicators, so these four indicators to delete. The "book audio and video teaching materials", "football sculpture", "high level sports team", "football teacher code of conduct" these indicators a large coefficient of variation, indicating that there is a big difference between students, so the students will further visit.

\section{Discussion}

On the basis of analyzing the concept and constituent elements of "culture", "football culture", "campus football" and "campus football culture", it is considered that the composition of football culture in Jiangxi independent school campus should include the following four aspects: school campus football material culture, system culture, behavior culture and spiritual culture. 
Jiangxi Province independent school campus football culture from the hardware facilities, management system, football courses, football community, the construction of school football team, as well as organized by the campus football league as the core of the football culture festival, to create a campus football atmosphere and other aspects of construction Good results and grades. For other vocational schools on the campus football culture construction play a reference role.

Through the investigation and analysis of the current situation of campus football culture construction in Jiangxi Province as an example, it is realized that the football exchange between the brothers and schools, the construction of high level football team, the entry of high level soccer tournament, the enrollment and transportation of high level soccer seedling Need to be improved, which to improve the level of school football development and school football career has a great impact. Through the campus football to further promote the popularization of campus football.

Taking Jiangxi Province as an example, the campus football culture construction conforms to the national campus football development thought, the concrete operation method desires to promote or draw lessons from. At the same time, he can further improve the vocational school campus culture level, rich vocational education, has a certain practical significance.

\section{References}

[1] Wang Qijun. Journal of Contemporary Sports Science and Technology, [J] Contemporary Sports Science and Technology ..2014, 4 (30): 119-119.

[2] Niu Yue Le. A Study on the Cultural Connotation and Construction Path of "Campus Football" - Taking Shanghai as an Example [J]. Liaoning Sports Science and Technology, 2015, 37 (1): 91-94.

[3] Xiao Jiachuan.Journal of Lanzhou College of Education. [J]. Journal of Sports, 2015, 31 (6): 165-166

[4] Liu Jianwei.Study on the Construction of Football Culture in Colleges and Universities [J]. Journal of Sports, 2014, 12: 8-9.

[5] Deng Hao. On the Cultivation of the Spirit of Student Cadres in Colleges and Universities after "90" [J]. Liaoning Sports Science and Technology, 2016, 34 (1): 113-119.

[6] Zhang xufang.On the Responsibility of Contemporary Teachers [J]. SCIENCE \& TECHNOLOGY. 2015 (20): 15-16.

[7] Zhao yanyan, zhang xiaoling.The Significance, Contents and Ways of Campus Football Culture Construction [J]. 2015 The 10th National Sports Science Conference Abstract (3), 2015.

[8] Wang Ge . Journal of Shenyang Physical Education Institute,.Study on the Current Situation, Problems and Countermeasures of Campus Football Activities in China [J]. 2011, 30 (2): 99-102

[9] Tang Wansong.Journal of Changsha University of Science and Technology (Social Science Edition), 2013,28 (3): 135-138

[10]Song Na Mei, Liang Xiao, Lin Yongbin.A Study on the Cultural Structure and Cognitive Differences of Soccer Culture in Middle School. Journal of Beijing Sport University [J]. 2017, 4 (20): 30-35

[11]Pu Yichuan. Value orientation and development path of football culture construction in China [J]. Journal of Mianyang Normal University. 2012, 31（3）: 103-107.

[12]Benno Torgler.The Economics of the FIFA Football World cup[J].KYKLOS,2004,57( 2) : 287 $-300$

[13]Cheng Guang.Constructing Campus Football Culture and Promoting Campus Culture Taste: An Analysis of Campus Football Culture Development [J]. 2014.(4):141-142. 